\title{
SISSEVAADE VARASESSE EESTI KEELE SÜNTAKSI OMANDAMISSE
}

\author{
Airi Kapanen
}

Ülevaade. Artiklis vaadeldakse kahe lapse spontaanse kõne andmestiku põhjal eesti keele süntaksi varast omandamist. Laste süntaksi varase arengu saab jaotada kolme perioodi strateegia järgi, mida laps esimeste mitmesõnaliste lausungite moodustamiseks kasutab. Andmetest nähtub, et eesti lapsed kasutavad mitmesõnaliste lausungite loomisel esialgu palju grammatikavälist vahendit, kordust. Lapse vanusega korduste hulk järk-järgult väheneb ja kõnesse ilmuvad kahest sõnast koosnevad, kuid süntaktiliselt sidumata lausungid. Viimasel vaatlusvahemikul leidub laste kõnes süntaktilistel baassuhetel, nagu subjekt-verb, verb-objekt põhinevaid lausungeid.

Võtmesõnad: lastekeel, kordus, tugiverbikonstruktsioonid, partiklid, eesti keel

\section{Sissejuhatus}

Kuigi on uuritud, kuidas laps lausemoodustuse omandab, pole praeguseni üht ainuõigeks peetavat lähenemist. Üksmeelel ollakse, et täiskasvanu ja lapse grammatika on erinevad ning et suhtlemisel on keeleomandamises tähtis roll. Eesti lapse süntaksiomandamist on ühe eesti keelt kõneleva lapse näitel oma diplomitöös uurinud Reili Argus (1994), mõnda keeleomandamise aspekti on vaadeldud ühes magistritöös (Argus 2008) ja paaris bakalaureusetöös (Lindsalu 1995, Parmas 2000). Kui lausete mõistmise oskust on võimalik uurida eksperimentaalsete meetoditega, siis lausete moodustamise oskuse uurimismaterjaliks sobivad ennekõike spontaanse kõne lindistused. Siinses artiklis soovitaksegi leida spontaanse kõne materjali põhjal vastuseid järgmistele küsimustele: 1) missugust strateegiat kasutab eesti keelt omandav laps ühest sõnast pikemate üksuste loomiseks, 2) kas varaste lausete puhul võib tähele panna mingeid korrapäraseid struktuure. Ühtlasi vaadeldakse kahe teoreetilise lähenemise sobivust eesti varase süntaksi omandamise kirjeldamiseks. 


\section{Kaks vaatenurka varase süntaksi omandamisele: Michael Tomasello ja Anat Ninio}

Praegustes lastekeeleuuringutes esilduvad kaks peamist süntaksi omandamise käsitlust. Ühe keskmes on konstruktsioonigrammatika, täpsemalt verb ja selle ümber koonduvad üksused (Tomasello 2003). Teine peab konstruktsioonide õppimise asemel lapse ülesandeks õppida iseseisvaid leksikaalseid üksusi ja seda, kuidas need grammatiliselt käituvad (Ninio 2011: 136). Anat Ninio järgi õpivad lapsed verbisõnavara koos verbide süntaktilise ja semantilise valentsiga; tema arvates on iga lapse varane süntaks erinev ning sõltub eri teguritest.

Michael Tomasello (2003) loodud nn verbisaare teoorias (ingl verb island theory) on lapse varane keel korrapäraselt koondunud üksikute verbide ümber, mille vahel seoseid ei ole: iga verb on omaette organiseeritud keeleüksus, justkui saareke muidu organiseerimata keelemustris. Keele omandamisel ja lausete moodustamisel tugineb laps kõnest kogutud verbispetsiifilistele konstruktsioonidele, milles on nn avatud koht eri nimisõnadele (ingl open nominal slot). Sisendkeele kaudu omandatud verbide põhjal loob laps konstruktsioone koos verbist sõltuvate süntaktiliste rollidega; iga verbi õpib laps kasutama teatud kindlat tüüpi konstruktsioonis (Tomasello 2003: 118). Nii võib laps täpselt ühe ja sama arenguperioodi vältel kasutada osa tegusõnu vaid üht tüüpi ja üsna lihtsas konstruktsioonis ning teisi mitmes ja keerukas. Näiteks kasutas Tomasello uuritud laps tegusõna "lõikama" (ingl cut) vaid ühes (cut + mõni nimisõna), kuid tegusõna “joonistama” (ingl draw) neljas konstruktsioonis (nt draw ...; draw ... on ...; draw ... for ...; ... draw on ...) (Tomasello 1992). Keelt omandav laps liidab verbi juurde sageli just nimisõna, kuna peale nimisõnade ta muid keelelisi abstraktsioone ei valda. Kui laps kasutab sama tegusõna uuesti, siis kordab selle kasutus eelmist, kuid veidi modifitseeritud kujul. Tomasello (2003: 121) järgi saab laste süntaktilist kompetentsust kõige paremini iseloomustada kui hulka üksteisest sõltumatuid verbisaarekesi isegi kuni vanuseni 2;6, paljudel lastel ka kuni vanuseni 3; o. Holger Diessel (2013: 10) on seepeale küsinud: "Kui lapse varased verbid on seotud kindlate konstruktsioonidega, siis kuidas õpivad lapsed verbe kasutama üle nende konstruktsioonide?” See on tähtis küsimus, sest kui laps oskab verbe kasutada väljaspool sõltumatuid konstruktsioone, on see teetähis, mis näitab veel üldisema verbi-argumendi struktuuri teket, mis väga suurel määral suurendab lapse suutlikkust kasutada süntaktilisi malle produktiivselt.

Ninio (2003: 19, 171) järgi pole ükski verb saareke, vaid lapse keelesüsteem on süsteem selle esimesest päevast peale. Tema sõnul ei tähenda lapse grammatika arenemine mitte verbisaarekeste ehk kindlate konstruktsioonide kogumist, vaid pigem arendab iga tegusõna oma minisüntaksi sõltumatuna teistest verbidest. See, kuidas lapse grammatika areneb, meenutab Ninio meelest linkimist veebi, kus üksused ühenduvad sarnasuse eri tahkude järgi. Tegusõnu õpivad lapsed nende sõnade semantilise ja süntaktilise valentsi järgi (Ninio 2011: 7), seega kombineeruvad lapse varased verbid kohe eri tüüpi konstruktsioonides ega moodusta nn saarekesi.

Ninio (2003) võttis Tomasello andmed ja leidis, et laps polnud 40\% verbidest, mis ilmnesid subjekti-verbi-objekti konstruktsioonis, enne esimest subjekti-verbiobjekti lauset üldsegi kasutanud. Peaaegu kolmandikul või neljandikul verbidel, mis moodustasid subjekti-verbi-objekti konstruktsioone, polnud olemas ei subjektiverbi, verbi-objekti või ühe sõna kordamise (ingl single-word antecent) kasutusi. 
Sellega näitas Ninio, et Tomasello kogutud andmed tema tütre Travise näitel ei toeta verbisaare hüpoteesi. Tema arvates loovad lapsed varased laused nii, et omandavad kohe koos verbiga selle valentsi. Laste varased laused põhinevad süntaksi baassuhetel, nagu subjekt-verb, verb-objekt, subjekt-verb-objekt, nagu eesti keeles emme loe, poiss kala, emme loe seda.

Kummaski vaadeldud käsitluses ei ole konstruktsioonide ja argumendistruktuuri baassuhete kõrval vaadeldud teisi tegureid, mis lapse varast süntaksit mõjutada võivad. Samas on näiteks lapse varase süntaksi omandamisel vaja vaatluse alla võtta ka grammatikavälised nähtused nagu kordus, tagasituletus, katkestus, põhja analoogia ja sulam (vt Dressler 2000, Dressler jt 2003: 393). Grammatikavälised nähtused keeles viitavad mehhanismidele, mida arvatakse olevat väljaspool grammatikat, nagu näiteks pragmaatika ja kognitiivsed võimed (Cannizaro 2012: 3).

\section{Meetod ja materjal}

Analüüsimaterjalina olen kasutanud kahe eesti keelt esimese keelena omandava lapse spontaanse kõne lindistusi. Martina kõnet on lindistatud 4 tundi 36 minutit, Andrease lindistusi on vaatluse all 5 tundi. Andrease spontaanne kõne on pärit CHILDES-i lastekeele andmepanga eesti lastekeele korpusest, korpuse on koostanud Andrease ema Maigi Vija. Martina kõne on lindistanud tema ema ja helifailid on litereerinud programmiga CLAN (ingl Computerized Language Analysis) ${ }^{1}$ Airi Kapanen. Nii Andreas kui ka Martina kasvavad peres, kus on ema, isa ja vend, ning kõik nende pereliikmed on eestlased.

Tabelis 1 on esitatud ülevaade salvestiste kestuse ning lausungite (sh kahe- ja enamasõnaliste) hulga kohta. Martina kõnes on kahe- ja enamasõnalisi lausungeid rohkem kui Andrease kõnes (vastavalt 1362 ja 472). Kahesõnaliste lausungite osakaal Martina kõnes suureneb vaatlusperioodi jooksul 62,7\%-lt 82\%-ni ja Andreasel 16,1\%-lt perioodi alguses 40\%-ni kõikidest lausungitest perioodi lõpus.

Tabel 1. Analüüsitud keelematerjal

\begin{tabular}{|c|c|c|c|c|c|c|c|c|c|c|c|}
\hline \multicolumn{6}{|c|}{ Andreas } & \multicolumn{6}{|c|}{ Martina } \\
\hline \multirow[t]{2}{*}{ vanus } & \multirow[t]{2}{*}{$\begin{array}{l}\text { lausun- } \\
\text { geid }\end{array}$} & \multirow[t]{2}{*}{ VKP } & \multicolumn{2}{|c|}{$\begin{array}{c}\text { kahe- ja } \\
\text { enama- } \\
\text { sõnaliste } \\
\text { lausungite }\end{array}$} & \multirow[t]{2}{*}{$\begin{array}{c}\text { salvestise } \\
\text { kestus }\end{array}$} & \multirow[t]{2}{*}{ vanus } & \multirow[t]{2}{*}{$\begin{array}{l}\text { lausun- } \\
\text { geid }\end{array}$} & \multirow[t]{2}{*}{ VKP } & \multicolumn{2}{|c|}{$\begin{array}{l}\text { kahe- ja } \\
\text { enama- } \\
\text { sõnaliste } \\
\text { lausungite }\end{array}$} & \multirow[t]{2}{*}{$\begin{array}{c}\text { salvestise } \\
\text { kestus }\end{array}$} \\
\hline & & & hulk & osakaal & & & & & hulk & osakaal & \\
\hline $1 ; 7,24$ & 460 & 1,166 & 74 & $16,1 \%$ & $1.00: 00$ & $1 ; 3,15$ & 423 & 2,308 & 265 & $62,6 \%$ & $56: 35$ \\
\hline $1 ; 8,10$ & 371 & 1,266 & 114 & $30,7 \%$ & $1.00: 00$ & $1 ; 5,18$ & 445 & 1,956 & 325 & $73,0 \%$ & 1.01:02 \\
\hline $1 ; 8,25$ & 308 & 1,195 & 61 & $19,8 \%$ & $1.00: 00$ & $1 ; 6,26$ & 238 & 2,245 & 170 & $71,4 \%$ & $35: 10$ \\
\hline $1 ; 9,11$ & 263 & 1,530 & 113 & $43,0 \%$ & $1.00: 00$ & $1 ; 9,19$ & 337 & 1,933 & 290 & $86,1 \%$ & $1.00: 25$ \\
\hline \multirow[t]{2}{*}{$1 ; 10,03$} & 271 & 1,574 & 110 & $40,6 \%$ & $1.00: 00$ & $1 ; 10,23$ & 378 & 3,388 & 312 & $82,5 \%$ & $1.03: 28$ \\
\hline & 1673 & & 472 & $28,2 \%$ & 5.00:00 & & 1821 & & 1362 & $74,8 \%$ & 4.36:00 \\
\hline
\end{tabular}




\section{Lausemoodustuse omandamise perioodid Andrease kõnes}

Andrease varase süntaksi võib eri vanuse kõnes domineerivate moodustusstrateegiate ja lausemallide järgi tinglikult jagada kolme perioodi. Esimest perioodi (vanus 1;7,24) iseloomustab korduste rohkus. Kordusena käsitan sõna kordamist lausungis, näiteks tudu tudu tudu [= magab], puppu puppu puppu [= nuppu], samuti kuulub korduse hulka ka sõnakuju mõningane varieerumine. Teisel perioodil (vanus $1 ; 8,10$ ja 1;8,25), loob Andreas grammatiliselt sidumata konstruktsioone, nagu hopp hopp ova [= orav], leli [= lõvi] sïa. Võrrelduna esimese perioodiga moodustab ta lausungeid, milles oskab ühele sõnale lisada teise. Kolmandal perioodil (vanus 1;9,11) kasutab laps sagedasti partiklit ka, näiteks kaane ka, teise ka, või $\boldsymbol{k a}$, kusjuures mõnes lausungis kordab laps ka partiklit ennast: saia $\boldsymbol{k a} \boldsymbol{k a}$, siil $\boldsymbol{k a}$ $\boldsymbol{k} \boldsymbol{a}$. Sel perioodil lisanduvad kordustele ja $\mathrm{ka}$-konstruktsioonidele omadussõnad: ilus ka, ilus torn, pähh juust ja määrsõnad: jälle uppi,jälle kopsti.

Kui morfoloogia omandamine on jagatud pre- ja protomorfoloogiliseks perioodiks (vt Argus 2008), siis paistab siin vaadeldud materjalist, et ka varases lausemoodustuses võib tinglikult eristada presüntaktilist ja protosüntaktilist perioodi, mida Andrease puhul esindaksid vastavalt eeltoodud esimene ja teine periood. Presüntaktilisel perioodil süntaksi omandamist veel ei toimu, kuid laps kasutab grammatikavälist lausemoodustusprintsiipi (ingl extragrammatical operation), nagu kordus (vt Dressler 2000). Protosüntaktilist perioodi iseloomustab selliste kombinatsioonide loomine, mis ei ole omavahel grammatiliselt seostatud, näiteks tädi kuri. Kui presüntaktilisel perioodil kordas laps üht ja sama sõna, siis protosüntaktilisel perioodil lisandub ühele sõnale teine, nimisõnale näiteks verb, kuid sõnad on süntaktiliselt veel sidumata, st verb ei ühildu ja nimisõna pole käänatud. Täiskasvanupärasest süntaksist veel rääkida ei saa, aga süntaktiliste protsesside eelkäijaid - leksikaalsete üksuste kombineerimist - võib ometi juba märgata.

\subsection{Andreas vanuses $1 ; 7,24$ - presüntaktiline periood}

Andrease kõne esimeses lindistuses $(1 ; 7,24)$ on 460 tema enda öeldud lausungit, neist kahe- ja enamasõnalisi on $74(16,1 \%)$. Andrease väljendite keskmine pikkus $(\mathrm{VKP})^{2}$ selles vanuses on 1,166 . Kuigi grammatika ei ole veel omandatud, oskab Andreas ühest sõnast pikemate üksuste moodustamiseks kasutada lihtsat grammatikaeelset võtet, kordust. Kõrvuti kordustega on Andrease varases kõnes palju sulameid, nagu eissaa [= ei saa], ettaa [= ei taha], kesse [= kes see on]. Ühegi korduses öeldud sõna puhul ei ole Andreas kasutanud muutelõppe, st ühest sõnast pikemate lausungite sõnad on ainsuse nimetavas ja verbide puhul kasutab Andreas vaid sõna tüve (nt uju).

Vanuses 1;7,24 on 74 mitmesõnalise lausungi hulgas 55 kordust (77\%), seega esinevad kordused tervelt kolmveerandis lausungitest. Andreas kordab nimisõnu (1), onomatopoeetilisi sõnu (2), verbe (3), arvsõnu (4), interjektsiooni (5).

(1) kala kala, kuts kuts [= koer koer]

(2) kiss kiss [= kass], njau njau njau 
(3) opa+opa [= hüppab], uju uju uju, kiika kiika [= kiikuda], kenne kenne [= kõndida], paia+paia [= paitama]

(4) üks üks üks

(5) aitäh aitäh

\subsection{Andreas vanuses $1 ; 8,10$ ja $1 ; 8,25$ - protosüntaktiline periood}

Vanuses 1;8,10 on Andrease 371 lausungi hulgas 114 kahe- ja enamasõnalist (30,7\%), mille hulgas on 88 kordust $(77,2 \%)$. Seega on ka selle perioodi lausungitest suurem osa selliseid, kus laps kasutab kordust. Andrease VKP on sel perioodil pisut suurem kui eelmisel, 1,266.

Vanuses 1;8,10 on Andrease kõnes 13 mitmesõnalist lausungit: hopp hopp ova [= orav], siia siia maha maha maha, aitäh uku uku [= nuku], leli [= lõvi] siia, emme aska! [= raske], Atsu Atsu Atsu Atsu aska [= raske], issi äh äh issika, tuhh [= tsuhh] tuhh [= tsuhh] emme, Antsu käru, kiisu üks kaks, emme käsi, torni Atsu [= Andreas] Atsu [= Andreas], hallo hallo hallo ole [= ei ole]. Võrreldes eelmise perioodi lausungitega on suur erinevus selles, millest kordustega lausungid koosnevad - nimelt ei korda laps nüüd mitte lihtsalt üht tüve, vaid kombineerib ka eri lekseeme. Kõigis neis lausungites on olemas kas tegija või objekt, üks elus või elutu olevus või ese, nt emme, issi, Atsu, hallo ('telefon'), ja teine sõna, millega selle kohta midagi öeldakse, miski, mis ilmselt on verbi asemel ja mis meenutab predikaati, nt aska ('raske') või siia.

Melissa Bowermani väitel moodustab laps paljud oma varased lausungid kahest nimisõnast (Bowerman 1973: 201). Samasugust strateegiat kasutab paljudel juhtudel ka Andreas. Nii sel viisil moodustatud lausungitele kui ka üksikule nimisõnale oskab Andreas aga liita omadussõna (6a), (6b), samuti moodustab Andreas lausungi, milles üksikule nimisõnale liidab kohasõna (7a)-(7c).

(6a) auh auh pai

(6b) tädi kuri

(7a) emme siia

(7b) otsu [= notsu, merisiga] sinna

(7c) leli [= lõvi $]$ siia

Enamik Andrease lausungeid pole grammatiliselt vormistatud ka järgmises lindistuses ehk kuu aega hiljem. Kordusi on endiselt üsna palju, nende hulgas on kõige rohkem kahesõnalisi (8), kuid on ka kolmesõnalisi kordusi (9).

(8) sisse sisse, peitu peitu, kommi kommi, uni uni

(9) silm silm silm, kutsu kutsu kutsu, hallo hallo hallo, kata kata kata [= karda]

Kõrvuti kordustega on materjalis nimisõna ja tegusõna kombinatsioone (10a), (10b), mis annavad tunnistust protosüntaktilise perioodi algusest: kombinatsioon moodustatakse kahest grammatiliselt sidumata sõnast; vormimoodustusoskust, mis on vajalik grammatikavahendite sidumiseks, veel ei ole.

(10a) mina mina iska [= viska]

(10b) otsu [= notsu, merisiga $]$ paista [= paistab] 
Vanuses 1;8,25 ilmub Andrease kõnesse esimene verbi ja noomeni konstruktsioon hallo hallo hallo ole [= ei ole] ning esimene verbi ja noomeni konstruktsioon, kus verbil on muutetunnus (autu tuli), samuti on Andrease kõnes üks verbi laiendiga konstruktsioon issi tuli kop-kop, milles ta on väljendanud ootust, et isa koju tuleks. Onomatopoeetilisele sõnale oskab Andreas lisada tegija (11a), (11b). Need lausungid annavad märku, et laps hakkab omandama esimest nn baassuhet ehk kasutab subjekti ja verbi (SV) kombinatsiooni (11b) või siis objekti ja subjekti (OS) kombinatsiooni (11a).

(11a) LAPS: tuhh tuhh [= tšuhh tšuhh] emme

EMA: emme peab laulma või ?

(11b) hopp hopp ova [= orav]

Ühel korral on ta korranud lausungi teist poolt (12), tegu võib olla soovi intensiivistamisega.

(12) LAPS: aitäh uku [= nuku] uku [= nuku]

EMA: nuku. [imitatiiv]

Vanuses 1;8,25 on 308 lausungi hulgas kahe- ja enamasõnalisi 61 (19,8\%), mille hulgas on 35 kordust (59,3\%). Võrrelduna perioodi algusega on kordusi 17,9 protsendi võrra vähem (77,2\%-lt perioodi alguses 59,3\%-le perioodi lõpus). VKP on 1,195. Sulamite (kessee, ettaha) hulk on palju väiksem kui vanuses 1;7,24 - neid esineb vaid paar korda.

Vaadeldud vanuses $(1 ; 8,10$ ja 1;8,25) iseloomustab Andrease kõnet korduste üsna suur hulk, kuid nüüd oskab Andreas ühele sõnale lisada nimisõna (13), verbi (14) või kohasõna (15).

(13) emme ova [= orav]

(14) iska [= viska], paista

(15) siia, sinna.

Kahe- ja enamasõnaliste lausungite moodustamisel on ülekaalus kordused, kuid Andrease kõnes on tavapäraste ühe ja sama sõna korduste hulgas selliseidki, mis koosnevad kahest eri sõnast, kusjuures Andreas on korranud kas mõlemat sõna (16) või neist üht (17).

(16) siia siia maha maha maha

(17) mina mina iska [= viska]

\subsection{Andreas vanuses $1 ; 9,11$ - nn ka-periood}

Vanuses 1;9,11 on Andrease öeldud 263 lausungi hulgas 113 kahe- ja enamasõnalist (43\%). Korduste hulk on vähenenud: 113 kahe- ja enamasõnalise lausungi hulgas leidub vaid 15 kordust (12,3\%). Uus joon Andrease kõnes on partikli $k a$ rohke kasutamine (18): kahe- ja enamasõnaliste lausungite hulgas on $33 \mathrm{ka}$-partikliga lausungit (29,5\%): teise ka, emme ka, kaane ka, kala ka, või ka, keemi ka, seda ka. 
Partiklit $k a$ võib Andrease puhul pidada verbi eelkäijaks. ${ }^{3}$ Andreas moodustab tugiverbiühendi, milles sõna $k a$ asendab väljendamata jäänud tegusõna. Sõnad, mida Andreas $k a$-partikliga koos kasutab, on käändsõnad nimetavas, omastavas või osastavas käändes. Näiteks ei ütle Andreas paneme teise, vaid teise ka ning emme paneb kreemi asemel ütleb keemi $k a$, nimetades tugiverbiühendist vaid objekti, millele tegevus on suunatud. Osal juhtudel kordab Andreas partiklit $k a$ ennast (18).

(18) teise ka ka, siil ka ka, saia ka ka

Vanuses 1;9,11 ilmub Andrease kõnesse lausung, milles on kolm eri sõna:

(19) Atsu [= Andreas] tuli [= diktofoni lambike] kätte

\subsection{Andreas vanuses 1;10,03 - korduste hulga vähenemine, süntaksi baassuhete kujunemine}

Lausungeid on selles vanuses lindistatud dialoogis kokku 271, neist mitmesõnalisi on 110. Lausungeid, milles Andreas kasutab ka-partiklit, on märgatavalt vähem kui eelmises vanuses - vaid 6,4\% (eelmises vaatlusvanuses 29,5\%).

Kahe- ja enamasõnaliste lausungite hulgas on 19 kordust $(16,5 \%)$, seega on korduste hulk võrrelduna vanusega $1 ; 8,10$ vähenenud 60,7\% võrra (vanuses $1 ; 8,10$ on kordusi Andrease kõnes 77,2\%, vt osa 4.2). Kõnesse on ilmunud pikemad lausungid, nt (20)-(24).

(20) emme loe seda

(21) issi loe seda

(22) ettaha sõrmeküüsi

(23) ettaha [= ei taha] sasti [= sahtlisse] ära

(24) emme tudu Atsu tudu

Vanuse 1;10,03 lõpus on esimesed selged märgid sellest, et laps moodustab süntaktilistel suhetel põhinevaid VO- (näited 20-23) ja SV-konstruktsioone (24).

\subsection{Kokkuvõte Andrease varastest lausungitest}

Vanuses 1;7,24 kasutab Andreas grammatikavälist moodustuspõhimõtet kordust, et luua pikemaid üksusi (skemaatiliselt võiks neid tähistada näiteks AA, BBB). Enamasti moodustab Andreas lausungeid, milles on kaks või kolm samakujulist sõna. Lisaks kordustele on Andrease kõnes palju sulandunud sõnu. Võrdluseks: vanuses $1 ; 8,10$ on kordusi Andrease kõnes 88 (77,2\%), vanuses 1;8,25 on 35 kordust (59,3\%), vanuses 1;9,11 oli 113 lausungist 15 (=12\%) ja vanuses 1;10,03 oli 110 lausungist 19 (17\%). Osakaal on arvutatud kahe- ja enamasõnaliste lausungite hulgast. Korduste osakaal lapse kõnes väheneb, kui laps saab vanemaks, seejuures näiteks paari kuuga üsna kiiresti: $77,2 \%$-lt 17\%-le.

3 Lapse kõnes võivad verbi funktsioonis esineda sõnad, mis kuuluvad mõnda teise sõnaklassi, eriti juhul, kui lapse 


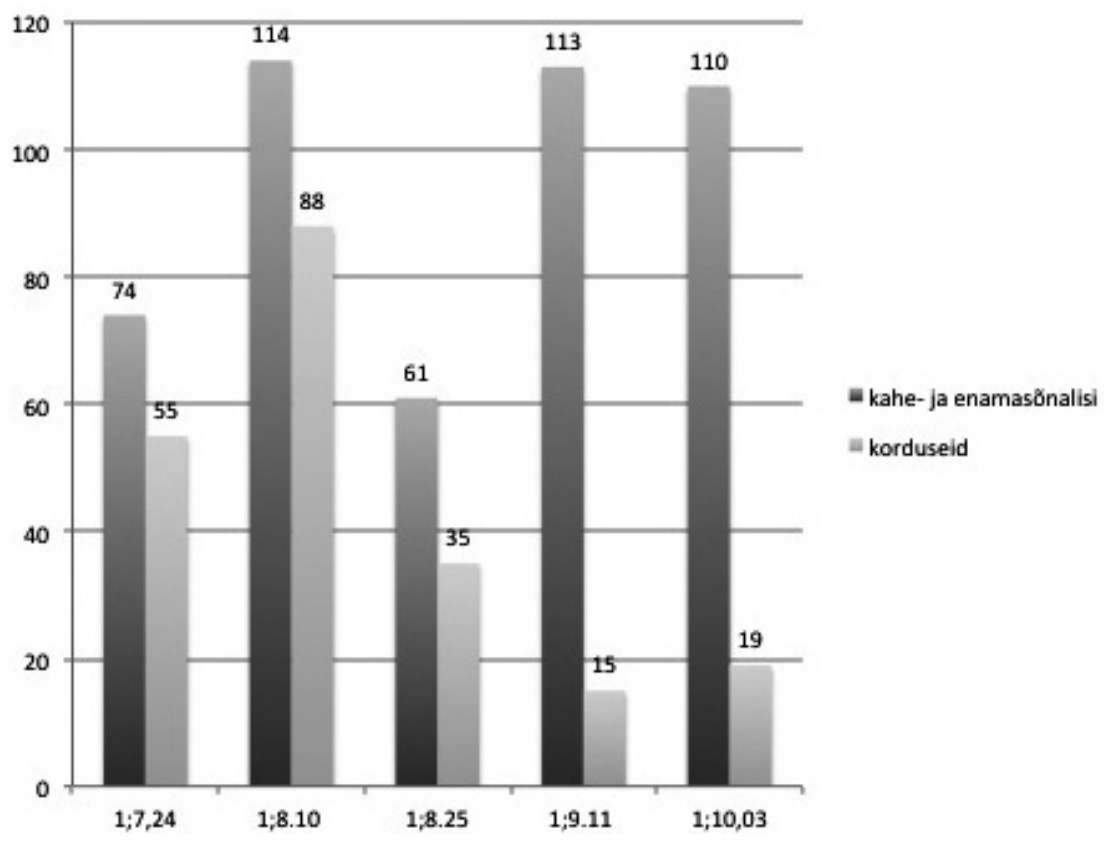

Joonis 1. Korduste arv kahe- ja enamasõnaliste lausungite hulgas Andrease kõnes eri vanusevahemikes

Vanuses 1;8,10 korduste hulk suureneb (vt joonis 1), kuid nüüd oskab Andreas liita esimes(t)ele sõna(de)le teise lekseemi, näiteks auh auh pai, tuhh tuhh emme (AAB); aitäh uku uku (ABB). Perioodi lõpupoole, vanuses 1;8,25, hakkab korduste hulk vähenema - 77\%-lt langeb korduste osakaal 59\%-ni - ning Andrease kõnesse tekib esimene verbi-nimisõna konstruktsioon ja nimisõna-verbi-omadussõna konstruktsioon.

Nn $k a$-perioodil $(1 ; 9,11)$ kasutab Andreas palju partiklit $k a$, õppides sel viisil looma sihilist konstruktsiooni, näiteks keemi ka tähendab 'paneme kreemi ka'. Vanuses 1;10,03 on korduste hulk võrrelduna varasemate vaatlusvahemikega märkimisväärselt vähenenud ja on hakanud kujunema süntaktilised baassuhted: verb-objekt ja subjekt-verb.

Lause moodustamist harjutab Andreas justkui tükkide kaupa: ta kasutab kordusi ja vanuse suurenedes oskab kordusele lisada uue elemendi. Prototüüpseks peetav lause, milles on alus, öeldis ja sihitis (nt Poiss püüab kala), on vaatlusaluses materjalis esialgu realiseerunud kahe eraldi lausungina, nt kala piia [= püüa] ja poiss kala.

Andrease kõnes esinevad verbid enamasti SV-konstruktsioonis: issi tuli, notsu kadu, tuhti paistab, otsi kulli, kala piia, palli osti, tädi aata [= vaata], tooli istu, tita rooli. On ka üksikuid VO-konstruktsioone: otsa sai mann [= vann], osta keemi, ei taha juustu.) Esimesed verbi valentsi põhised konstruktsioonid tekivad Andrease kõnesse seega vanuses $1 ; 8,25$, rohkem on neid alates vanusest 1;9,11. Andrease varastest lausungitest on näha, et ta kasutab eri verbe eri tüüpi kombinatsioonides, kindlaid ühe verbi ümber koonduvaid konstruktsioone märgata ei ole. 


\section{Lausemoodustuse omandamise perioodid Martina kõnes}

Esimesele vaadeldud perioodile on iseloomulikud kordused. Kõrvuti tavapärase kordusega, kus Martina kordab sõna selle vormi muutmata, esineb tema kõnes sellinegi kordus, milles ta kordab üht ja sama sõna väikeste erinevustega. Sõna varieerub tavaliselt kolm korda, nt märgi väigi väägi [= värvi värvi värvi]. Osas lausungeist kasutab Martina peegelmalli (vt 5.1).

Teisel perioodil jätkub korduse kasutamine ja lisandub rohkelt määrsõnu: kinni, lahti, veel, koos, siit, seal, juurde, bäl [= veel]. Kolmas on partiklite periood, kus kõnesse ilmub suurel hulgal partikleid, nagu ka,jälle, küll, ära. Neljandat vaadeldud ajavahemikku Martina kõnes võib nimetada pikkade lausungite perioodiks, samasse vahemikku jääb ka sihilise konstruktsiooni moodustamine.

\subsection{Martina vanuses $1 ; 3,15$ - presüntaktiline periood}

Martina 423 lausungi hulgas on 265 kahe- ja enamasõnalist lausungit (62,6\%), mille hulgas peaaegu pooled on kordused (127 lausungit; 48,5\%). VKP vanuses $1 ; 3,15$ on 2,308 .

Martina on korranud tegusõnu (25a)-(25e) ja nimisõnu (26a)-(26e).

(25a) eita eita ei taha

(25b) ängi ängi [= mängi mängi]

(25c) kaia kaia [= käima käima]

(25d) lau lau [= laulma laulma]

(25e) aata daata [= vaata vaata]

(26a) mai mai [= mari mari]

(26b) võthi võthi [= mütsi mütsi]

(26c) toma toma [= tomat tomat]

(26d) kiidu kiisu [= kiisu kiisu]

(26e) lill lill lill

Näidetes (27a)-(27e) ütleb Martina ühes lausungis ühe sõna kolm kuju - tema lausungid on justkui sõna õige fonoloogilise kuju otsimised.

(27a) emme märgi väigi väägi [= emme värvi värvi värvi]

(27b) indi ninnis inni [= lindistab lindistab lindistab]

(27c) kuutsi mõmmi paatsi uutsi [= pluusi mõmmi pluusi pluusi]

(27d) ou uu õu [= õun õun õun]

(27e) koos koss [= koos koos]

Sama võtet kasutab Martina ka pikemate üksuste puhul, korrates kahesõnalist fraasi:

(28) emme au emme auk emme auki [= emme arvuti emme arvuti emme arvuti]

(29) kaks onu kat onu kak [= kaks onu kaks onu kaks]

(30) ise kati ise kati ise [= ise katki ise katki ise]

(31) te tee iia te tee te tee [= see see siia see see see see] 
Martina kõnes on märgata rütmilisust (32)-(34). Osas lausungitest, nt (32)-(34), on Martina kasutanud omalaadset malli, mida võib nimetada peegelmalliks: ta ütleb lausungi esimese poole, lisab uue sõna ja kordab pärast seda lausungi esimest osa.

(32) bipa papa õue õue bipa papa [= tipa tapa õue õue tipa tapa]

(33) bipa bipa tita bipa papa [= tipa tapa tita tipa tapa]

(34) te te katki katki tee kati [= see see katki katki see katki]

Samal perioodil on Marina kõnes kahesõnalisi lausungeid, nagu emme luue [= loe], emme buue [= loe], emme atta [= aita], nimisõna ja tegusõnaga lausungeid mõmmi teep [= teeb], eeku aata [= seelikut ei taha], oo pall [= oo pall] lendab ning määrsõnaga lausungeid, nagu ööbi [= nööbi] kinni, kuku [= luku] lahti.

Martina on korranud lausungites tegusõna (35) ja nimisõna (36a), (36b).

(35) diku vaata vaata [= diktofon vaatab vaatab]

(36a) emme mah mah [= emme mahl mahl]

(36b) poss poss käes [= poiss poiss käes]

Martinal on esimeses lindistuses, vanuses 1;3,15, SV-konstruktsioon mõmmi teeb ja juba järgmises (vanuses $1 ; 5,18$ ) moodustab ta SVO-konstruktsioonid issi annab tomatit ja emme sööb kohvi. Lausungite hulgas on ka VO-konstruktsioone, nagu laul kikuu [= laulda diktofonile], äita [= näita] mängu ja SO-konstruktsioone, näiteks diku [= diktofoni] aada [= vaatan]. Martina selle vanuse lausungites on nimisõna enamasti eespool, järgneb verb.

\subsection{Martina vanuses $1 ; 5,18$ - protosüntaktiline periood}

Vanuses 1;5,18 on Martina kõnes kokku 445 lausungit, mille hulgas kahe- ja enamasõnalisi on 325 (71\%). Viimaste seas on 29 kordust $(9,1 \%)$. Korduste hulk on võrrelduna eelmise vaatlusvanusega (neid oli 48,5\%) suurel määral - 39,4 \% võrra vähenenud. Ka-partikliga lausungeid on Martina kõnes kahe- ja enamasõnaliste lausungite hulgast 14 (3,15\%). Tema VKP vanuses $1 ; 5,18$ on 1,956 (vt tabel 1).

Andreasel algas protosüntaktiline periood (vt osa 4.2) vanuses 1;8,10, mil tema VKP oli 1,266. Korduste osakaal Martina ja Andrease kõnes protosüntaktilisel perioodil erineb: Andrease kõnes on sel perioodil kordusi 77,2\% ja Martinal 9,1\% kahe- ja enamasõnaliste lausungite hulgast, mille osakaal kõigist lausungitest on vastavalt 30,7\% ja 71\%. Kui Andreas kordab vaid üksiksõnu, siis Martina kõnes esineb lisaks seda tüüpi kordusele ka pikemate fraaside kordamist. Lisaks selgub lindistustest, et Martina kõne protosüntaktilise perioodi kõne erineb Andrease protosüntaktilise perioodi kõnest selle poolest, et Martina kasutab verbe märkimisväärselt rohkem.

Martina jätkab nii üksiksõnade (37a)-(37c) kui ka fraaside (41a)-(41c) kordamist.

(37a) teda teda

(37b) põõma põõmah [= pall]

(37c) tasa tasa

(38a) emme istud emme istud

(38b) tomati kaa tomati kaa 
(38c) etaha linnu [= Intsu] tomat eetahha innu [= Intsu] tommat iiuu eetaha Innu $[=$ Intsu $]$ tomat

Vanuse 1;15,18 kõnes on võimalik täheldada määrsõnade suhtelist rohkust: kinni, lahti, veel, koos, siit, seal,juurde, bäl [= veel]. Peale korduste on kõnes lausungeid, nagu emme koos õue, issi koos õue, issi anna veel tomatit, Makkus külla ilähe [= ei lähe].

Süntaktilistest baassuhetest esineb Martina selle vanuse kõnes VO-konstruktsioone etaha [= ei taha] Intsu tomat, SO-konstruktsiooni äku pokandit [= jänku (tahab) porgandit], SV-konstruktsioone dipuki [= diktofon] käib, kuid on ka SVOkonstruktsioone, nagu mina taha uid [= võid], issi anna veel tomatit.

\subsection{Martina vanuses 1;6,26 - pikkade lausungite kordamise periood}

Vanuses 1;6,26 on Martina 238 lausungi hulgas 170 kahe- ja enamasõnalist lausungit (71,4\%), Martina VKP selles vanuses on 2,245 (vt tabel 1).

Kõrvuti sõnakordusega, nagu ukkimannaa ukkimanna [= rukkimanna rukkimanna], on on, nämm nämm nämm nämm, ei saa ei saa, on Martina kõnes vanuses 1;6,26 üsna palju selliseid lausungeid, milles ta on korranud pikemat üksust:

(39a) emme minu minu vitamiinid on üleval emme minu vitamiinid on üleval

(39b) suurt võid ei ole siin a suurt võid ei ole siin

(39c) ele vandidoo elevant joo elevand joo

(39d) ja mapanin nii palju võid panin nii palju vuiid

(39e) ei taha emaa pese selle nugaa ua pesee ära pese nugaa

(39f) nüdon puhas emme nüdongi puhas emme nüd on emme nüdon kõik

\subsection{Martina vanuses $1 ; 9,19$ - partiklite periood}

Vanuses 1;9,19 on 337 lausungi hulgas 290 kahe- ja enamasõnalist lausungit $(86,1 \%)$, VKP selles vaatlusvanuses on 1,933 (vt tabel 1). Martina lausungitesse ilmub suurel hulgal partikleid, ta kasutab partikleid ka, jälle, küll, ära, samas kui Andreasel oli ühe partikli, $k a$ periood.

Lausungite üldhulgast on Martina kasutanud partiklit $k a 23$ lausungis $(8,1 \%)$, partiklit ära 11 lausungis (3,9\%) ja partiklit küll 45 lausungis (15,8\%). Partikkel ära väljendab nii perfektiivsust (lõhkus pesa ära, lahendas ülesande ära) kui ka suunda (sõitis ära) (EKG II: 21). Martina kõnes väljendab partikkel ära perfektiivsust (tudusin ära, emme pesid ära juba nüüd) ja keeldu (äla pane ise või), mõnel juhul on Martina kasutanud sõna ära pöörduva eitussõnana (40d).

(40a) ma tudusin äraa jubaa

(40b) ää äla pane seda patsi kõvasti

(40c) äla pane ise või

(40d) emme ära anna see emme ära anna seda isee

(40e) emme pühki ära

(40f) tee [= see] ka ära 
(40g) emme va mängi seda mõmmi nuusit [= nõusid] emme ära pese seda nõud

(40h) emme pesid ära uba nüüd

Partikli $k a$ kasutuse puhul on märgata, et osa juhtudel kasutab Martina ka-partikliga samas fraasis veel verbi. Siin ilmneb erinevus Andrease ja Martina kõne vahel, Andreas lisas ka-partikli nimisõnale, nt emme ka, keemi [= kreemi] ka, kaane ka, Martina aga verbile:

(41a) emmee laseb ka endale vett

(41b) kätele tehakse ka massa massa

(41c) nii kas sa tahad ka seda kohvii?

(41d) emme laseb ka endale vett

Vaid üksikutes lausungites on Martina seostanud $k a$-partikli nimisõnaga:

(42) mis ma tegin teise või ka

(43) mul ka vesi

(44) kohvi ka kohvitass

(45) elevandil olid oma puu elevandid olid ka puuris olid küll

Partikkel küll ei saa esineda omaette vooruna, ta on rõhutav, vastust kinnitav sõna (EKSS). Sellises funktsioonis esineb partikkel küll Martinagi kõnes:

(46a) EMA: aa sinu võti on seal jaa

LAPS: on küll

(46b) EMA: vaata kui siin tu punane tuli põleb, siis ta käib, emme pani käima LAPS: emme pani käima

EMA: mhmh

LAPS: pani küll

(46c) EMA: juba läks vitamiin suhuu

LAPS: läks küll

(46d) LAPS: kus on Saalema [= Saaremaa] või?

EMA: kapi peal

LAPS: emme või on seal seal on Saame [= Saaremaa]

LAPS: emme seeon võinuga on küll

(46e) EMA: kas sa palun on sul mahti nüüd ööö see Martiina turvatool ümber tõsta minu autosse?

ISA: mhmh

LAPS: issi emme mme autosse tõsta sedaa [= seda] saab küll

Partikli jälle tähendus toob esile sündmuse kordumise, st olemasolevale hulgale lisandub midagi juurde.jälle tähendus kordumisele viitavas funktsioonis on seotud ajalise tähendusega, kuid väljendab ka lisamise aspekti (Parm 2007: 29). Martina kõnes esineb partikkel jälle eelviidatud funktsioonides:

(47a) tuleb jälle

(47b) seon [= see on] kiisu pluus jälle

(47c) emme teeb jälle endale kohvi 
Süntaktilistest baassuhetest esinevad sel perioodil Martina kõnes peamiselt SV-ja VO-konstruktsioon (idaa [= ei taha] ukkimannaputtu, võinoa ka võtta kätte, tahan ise võileiba panna), ent on ka SVO-konstruktsioone (mina oian koa [= hoian ka] seda, emme mina jõin täna niïpalju vett, mina söön sedaa).

\subsection{Martina 1;10,23 - pikkade lausungite moodustamise periood}

Lausungeid on Martina kõnes vanuses 1;10,23 kokku 378, millest enamiku moodustavad kahe- ja enamasõnalised (312, mis on $82,5 \%$ lausungite koguhulgast). Võrdluseks meenutame, et vanuses 1;3,15 oli kahe- ja enamasõnalisi lausungeid 62,6\%). VKP on Martinal selles vanuses 3,388 (vanuses 1;3,15 oli VKP 2,308).

Kõrvuti sellega, et säilinud on kõik varasema vanuse kõnele iseloomulikud jooned - sõnade (48) ja pikemate fraaside kordamine (49a), (49b) ning partiklite ka, ära, küll,jälle kasutamine -, oskab Martina moodustada üsna pikki lausungeid, milles ei ole pause (50)-(52). Need on kuuldavale toodud ilma hingetõmbepausita, mistõttu ei ole võimalik lausungipiire tuvastada.

(48) pese pese pese

(49a) ma tulen siia emme kuvvale tulen siia emme kõrvale tasakaalu

(49b) laa laa laa ma võtan väikse pilli võtan väikse pilli võtan väikse pilli

(50) veel kallan Martiina ära nüüd ma panen karbi kinni emme nüüd ma panen Hello Kiti kaabi karbi kinni teist karp kinni siis siis iise ja kuasti jäi läinud vaata see läks juba kinni kas kiisu pusle läks kinni?

(51) jälle uhupalli kiisu jälle õhupall see käib siia sinna paikkah emme kus see käi las see olla siin las see iiah kuall nüüd paigal teise asja veel siia see sai valmis

(52) teeb kalp kalp kalp kalp nüüd on Lote söööök see on Lote söök ma söön Lote söögi ära

Ka vanuses 1;10,23 moodustab Martina sihilisi konstruktsioone:

(53a) pani pudu [= pudru] potti vett

(53b) ma kisu puslet hoida

(53c) ma võtan hoopis tudulapi eest

Selle perioodi lindistuses on olemas SV-baassuhe (issi paneb), VO-suhe ja sageli ka SVO-suhe (Martina võtab selle).

\subsection{Kokkuvõte Martina varastest lausungitest}

Martina kasutab ühest sõnast pikemate lausungite moodustamiseks kordust ja hakkab üsna ruttu moodustama pikemaid üksuseid, mida samuti kordab. Näib, et Martina omandab süntaktilise rütmi, mille täidab igas vanuses parajasti tema käsutuses olevate leksikaalsete vahenditega. Osas lausungites kordab Martina küll üht ja sama sõna, ent varieerib sageli selle kuju, näiteks märgi väigi väägi [= värvi värvi värvi], emme au [= arvuti] emme auk [= arvuti] emme auki [= arvuti]. Samuti 
kasutab Martina kordamisel n-ö peegelmalli, kus ta ütleb lausungi esimese poole, lisab uue sõna ja kordab pärast seda lausungi esimest osa.

Martina kõnes paistab silma partiklite nagu ka, küll, jälle, ära rohke kasutamine, neist eriti sagedasti kasutab Martina partiklit küll, mis rõhutab, kinnitab vastust. Viiest vaadeldud perioodist neljanda lõpul oskab Martina luua sihilist konstruktsiooni. Tema pikimas lausungis on 38 sõna.

Nagu Andrease, nii ka Martina kõnes ei leidunud ühe kindla verbi ümber koondunud konstruktsioone, kõik verbid kombineerusid eri hulgal muude sõnadega. Vaadeldud ajavahemiku lõpuks olid olemas VO-, SV- ja VO-konstruktsioon ning ka SVO-konstruktsioon.

\section{Kokkuvõte}

Eesti keelt omandavate laste varast süntaksit iseloomustab siinse uurimuse materjali põhjal kõigepealt kordus, mis on esialgu lausete moodustamise põhimoodus: laps kasutab neid leksikaalseid vahendeid, mis tal kindlas vanuses olemas on, ja kordab üht sõna mitu korda. Kui laps saab vanemaks, siis korduste hulk tema kõnes väheneb, seega on kordusel kindel roll just süntaksi omandamise varases järgus. Selgub, et rütm on peale sõnade omandamise tähtis ka varaste mitmesõnaliste lausungite puhul - laps kordab fraase, mis koosnevad kahest ja enamast sõnast, sageli justkui kindla rütmi järgi, nt kordub esimesena öeldud sõna või sõnapaar pärast uut elementi uuesti. Varasele keeleomandamisele on järgmisel etapil iseloomulik partiklite $k a$, küll, ära,jälle rohke kasutamine. Partikkel $k a$ näib asendavat mõnel juhul tugiverbikonstruktsiooni verbi (vt Muischnek 2004), mida keelt alles omandav laps ei ole õppinud veel ütlema. Kui Andreas kasutas põhiliselt partiklit $k a$, siis Martina kõnes on neid vaadeldud perioodil suurem valik. Erinevus kahe lapse varase lausemoodustuse arengus puudutab veel ka omajasuhete arengut. Nimelt leidub Martina kõnes omastavakujulise täiendiga nimisõnafraase juba vanusest 1;3,15. VKP väärtuse kohta on võimalik tähele panna, et Andreasel algas süntaksi baassuhete kujunemine, kui VKP oli 1,54, Martinal, kui VKP oli 2,3.

Andrease kõnes (vanuses 1;8,25) võib täheldada üksikuid lausungeid, kus üht ja sama verbi on kasutatud ühesuguses konstruktsioonis (buss tuli, auto tuli), kuid sedalaadi n-ö saarekesed on ainsad. Mõlema lapse kõnes esinevad üksikud tegusõnad, millega paaril korral on moodustatud ühesugune konstruktsioon, ei toeta Tomasello väidet, et varane keel on $\mathrm{k}$ o r r a p ä r a s e l t koondunud üksikute verbide ümber.

Süntaksi baassuhete omandamine ehk selliste lausungite moodustamine, milles on subjekt-verb, verb-objekt, algab Andreasel vanuses 1;10,03. Martinal on sellised lausungid olemas kõigis vaatlusvanustes alates salvestiste algusest ( $m \tilde{m} m \mathrm{mi}$ teeb, 1;3,15).

Seega sobib Andrease ja Martina keelematerjali põhjal eesti keele süntaksi omandamise kirjeldamiseks verbisaare teooria asemel paremini Ninio vaatenurk, mille kohaselt põhinevad lapse varased laused pigem süntaksi baassuhetel, nagu subjekt-verb, verb-objekt, subjekt-verb-objekt. Eriti hästi on seda võimalik vaadelda Martina kõnematerjali põhjal, milles salvestiste algusest peale on võimalik näha selliste lausungite moodustamist, milles on subjekt ja verb (mõmmi teeb), subjekt, verb 
ja objekt (issi annab tomatit, emme sööb kohvi) või subjekt ja objekt (issi tomatit), kuid ka Andrease kõnes on võimalik jälgida samasugust moodustusprintsiipi (poiss püüab, poiss kala), mitte kindlaid tervikuna omandatud korduvaid konstruktsioone.

Kokkuvõtlikult näitab eesti laste varaste lausungite esmane analüüs, et varane lausemoodustus algab grammatikaväliste elementide, ennekõike korduste kasutamisest ja jätkub süntaksi baassuhete tekkimisega. Kui kordustega on saadud selgeks pikema lausungi fonoloogiline kuju või mahupiir, saab laps hakata seda täitma verbi argumendistruktuuril põhinevate tähendus- ja vormisuhetega.

\section{Lühendid}

O objekt

S subjekt

V verb

VKP väljendi keskmine pikkus

\section{Viidatud kirjandus}

Argus, Reili 1994. Lause areng ühe lapse keeles vanuseni 1,6-4,o. Lõputöö. Käsikiri nr 1225 Tartu Ülikooli eesti keele osakonnas. Tartu: Tartu Ülikool.

Argus, Reili 2004. Verbi eelkäijatest esimeste kolmeliikmeliste miniparadigmadeni eesti ja soome keele võrdlusel. - Helle Metslang (koost.), Maria-Maren Sepper, Jane Lepasaar (toim.). Toimiv keel II. Töid rakenduslingvistika alalt. Tallinna Pedagoogikaülikooli eesti filoloogia osakonna toimetised 3. Tallinna Pedagoogikaülikool, Eesti Keele Instituut. Tallinn: TPÜ kirjastus, 37-52.

Argus, Reili 2008. Eesti keele muutemorfoloogia omandamine. [Acquisition of Morphology in Estonian.] Tallinna Ülikooli humanitaarteaduste dissertatsioonid 19. Tallinn: TLÜ Kirjastus.

Cannizzaro, Courtney Leigh 2012. Early word order and animacy. http://www.let.rug. $\mathrm{nl} / \sim$ hendriks/papers/cannizzaro.pdf (9.1.2014).

Diessel, Holger 2013. Construction grammar and first language acquisition. - Graeme Trousdale, Thomas Hoffmann (Eds.). The Oxford Handbook of Construction Grammar. Oxford: Oxford University Press, 347-364.

Dressler, Wolfgang U. 2000. Extragrammatical vs. marginal morphology. - Ursula Doleschal, Anna M. Thornton (Eds.). Extragrammatical and Marginal Morphology. Munich: Lincom Europa, 1-10.

Dressler, Wolfgang U.; Kilani-Schoch, Marianne; Klampfer, Sabine 2003. How does a child detect morphology. - R. Harald Baayen, Robert Schreuder (Eds.). Morphological Structure in Language Processing. Trends in Linguistics, studies and monographs 151. Mouton de Gruyter, 391-427.

EKSS $=$ Eesti kirjakeele seletussõnaraamat I-VII. 1988-2007. [The Explanatory Dictionary of Estonian.] Eesti Keele Instituut. Tallinn: Eesti Keele Sihtasutus.

Lindsalu, Elo 1995. Liitlaused ja nende sidumine eesti lastekeeles. Magistritöö. Tallinna Pedagoogikaülikooli (al. 2005 Tallinna Ülikool) eesti filoloogia osakond.

Metslang, Helle 2001. On the development of the Estonian aspect: the verbal particle ära. Ö. Dahl, M. Koptjevskaja-Tamm (Eds.). The Circum-Baltic Languages. Typology and Contact. Vol. 2. Grammar and Typology. Amsterdam-Philadelphia: John Benjamins, 443-480.

Muischnek, Kadri 2004. Eesti keele tugiverbid ja nende mõju lause ehitusele. [Estonian support verbs and their impact on the syntactic structure.] - Emakeele Seltsi aastaraamat, 50, 11-38. 
Ninio, Anat 2003. No verb is an island: Negative evidence on the verb island hypothesis. Psychology of Language and Communication, 7 (1), 1-21. http://www.plc.psychologia. $\mathrm{pl} / \mathrm{plc} / \mathrm{plc} / \mathrm{contents} /$ fulltext/07-1_1.pdf (23.2.2014).

Ninio, Anat 2011. Syntactic Development, its Input and Output. Oxford: Oxford University Press. http://dx.doi.org/10.1093/acprof:oso/9780199565962.001.0001

Parm, Sirli 2007. Partiklite veel, juba, alles, jälle tähendused eesti kirjakeeles. Magistritöö. Tartu: Tartu Ülikool. http://dspace.utlib.ee/dspace/handle/10062/2932 (5.3.2014).

Parmas, Viktoria 200o. Ühe eesti lapse küsilause areng (Ingel-Brit 1;6-2;2). Magistritöö. Tallinn: Tallinna Ülikool.

Tomasello, Michael 1992. First Verbs. Case Study of Early Grammatical Development. Cambridge University Press. http://dx.doi.org/10.1017/CBO9780511527678

Tomasello, Michael 2003. The New Psychology of Language. Cognitive and Functional Approaches to Language Structure, Vol. 2. Mahwah, NJ/London: Lawrence Erlbaum.

\section{Võrgumaterjalid}

CHILDES - Child Language Data Exchange System. http://childes.psy.cmu.edu/ (24.2.2014). Using CLAN. http://childes.psy.cmu.edu/clan/ (24.2.2014).

Airi Kapanen (Tallinna ülikool) uurimisvaldkond on esimese keele süntaksi omandamine eesti keelt emakeelena kõnelevates peredes.

Õismäe tee 140-64, 13511 Tallinn, Estonia

airikapanen@gmail.com 


\section{INSIGHT INTO THE EARLY ACQUISITION OF SYNTAX IN ESTONIAN}

Airi Kapanen

Tallinn University

This article examines syntax acquisition in Estonian on the basis of the spontaneous speech data of two children acquiring Estonian as their native language. The early utterances and the acquisition of syntax by children can be divided into three stages according to the strategy that a child uses to produce multi-word utterances: the use of antecedents, the particle period and the formation of the basic verbal argument structure constructions.

The data indicates that Estonian children often use an extragrammatical operation, antecedents, while they iterate two- and multiword utterances. As children get older, the number of antecedents is gradually reduced and a substantial amount of particles and syntactically not bound two-word utterances appears. Simultaneously, child speech features some basic verbal argument structure constructions, subject-verb (SV), verb-object (VO) and subject-verb-object (SVO), and the number of such constructions increases gradually.

Keywords: child language, repetition, support verb constructions, particles, Estonian 